\title{
Performance Assessment of Waste Fiber-Reinforced Mortar
}

\author{
C. Gonilho-Pereira ${ }^{1, a}$, P. Faria ${ }^{2, b}$, R. Fangueiro ${ }^{3, c}$, A. Martins ${ }^{1, d}$, P. Vinagre ${ }^{1, e}$, \\ S. Ratão ${ }^{1, f}$ \\ ${ }^{1}$ Polythecnic Institute of Setubal, Barreiro College of Technology, 2839-001 Lavradio, Portugal \\ ${ }^{2}$ Nova University of Lisbon, Dept. Civil Engineering, 2839-516 Caparica, Portugal \\ ${ }^{3}$ University of Minho, School of Engineering, 4800-058 Guimarães, Portugal \\ ${ }^{a}$ cristiana.pereira@estbarreiro.ips.pt (corresponding author), ${ }^{b}$ paulina.faria@fct.unl.pt, \\ crfang@det.uminho.pt, dana.martins@estbarreiro.ips.pt, ${ }^{\mathrm{e}}$ pvinagre.435@estbarreiro.ips.pt, \\ esratao.1315@estbarreiro.ips.pt
}

Keywords: waste fibrous material, recycling, fiber-reinforced mortar, mortar characterization, compatibility.

\begin{abstract}
In this paper an experimental work is presented which main objective is the evaluation of the influence of different percentages of waste fibrous materials usage on the performance of fiberreinforced mortars. Moreover, the influence of binder type is evaluated. Therefore mortars were produced with two different binders - cement and powder hydrated lime. Mortars performance evaluation was carried out through flow table and plunger penetration consistency, dynamic modulus of elasticity, flexural and compressive strength, capillary absorption, drying index and adherence tests. The benefits revealed in some characteristics of both mortars by the use of waste fibers are discussed.
\end{abstract}

\section{Introduction}

The increase of extraction and processing of natural resources is accompanied by the formation of significant amount of waste materials - only $1 / 3$ of extracted raw material is used to produce industrial output; the rest $2 / 3$ turn into waste materials and by-products [1].

Comparative studies on recycling and waste management options reveal significant environmental advantages of recycling over landfilling and incineration. Therefore, the cost, quality and availability of raw materials became of paramount importance and a significant number of companies are currently developing secondary manufacturing processes for their waste materials and by-products.

Among the industries producing wasting materials, textile industry produces large amounts of waste which are used with success in second-line products. Although the usage of waste fibrous materials in the building construction industry is already a reality, namely in the production of thermal and acoustic insulation panels, their disposal in landfills is still a reality. Waste fibrous materials are accumulated at textile factories and the technical challenge is the search for new applications for waste products of fibrous materials.

An interesting application seems to be fiber-reinforced mortar mixtures for masonry applications, new or replacing existing mortars, which have not been extensively studied.

The selection of appropriate mortar mixtures is an important research problem once four main factors should be considered in their design - durability, flexural resistance, compatibility and, consequently, economy. Fiber reinforced cement based mortars have been suggested as one of the most effective methods to improve performance behavior, namely: mechanical [2]; shrinkage, expansion and related phenomena which lead to cracks [3]; and durability [4]. Fibers present the ability to act as a bridge between the grains of the mortar matrix. When the fibers are uniformly distributed into the mortar, plastic shrinkage may be minimized and micro cracks are prevented from developing into macro cracks. Therefore the consequent strength reduction, water intake increase and subsequent decay of the mortar by freezing-thawing cycles, and aesthetic involvements may be avoided. 


\section{Material and mortar samples preparation}

The waste fibers used in the present research work derive from waste fibrous materials collected from textile industries in the outskirt of Minho area, in the northern part of Portugal. The fiber mass consists of many unknown fibers, since it was collected from several textile industries producing a various range of textile qualities and consequently using many different fiber materials and fiber/fabric treatments (Figure 1. a)). The collected waste fibrous material was used for the production of nonwovens and the waste fibers used in this research work are manufacturing wastes of the nonwoven manufacturing process (Figure 1. b)) - microfibers.

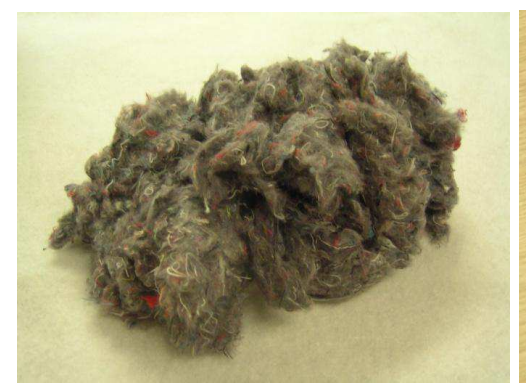

a.) waste fibrous materials.

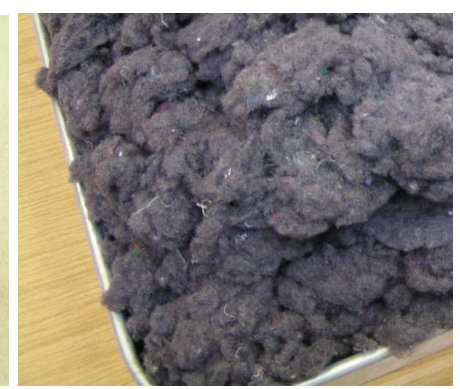

b.) waste fibers.

Figure 1. Textile industry waste material:

The identification of the waste fibers content was performed according to [5]:

i) Burning test: aims to distinguish whether the unknown fibers are of natural or synthetic origin. Burn examination cannot be used to identify different fibers of the same chemical composition [32]. The specimen was held over a clean flame from gas burner or from a wooden match. The fiber smell, flame colour, burn behavior, ash formation and smoke were examined. It was suspected that it contained a considerable part of natural fibers, as well as some synthetic polymers.

ii) Chemical test: $75 \%$ Sulphuric acid, $\mathrm{H}_{2} \mathrm{SO}_{4}$, was used to quantify natural fibers, since cellulosic fibers are soluble in acids. Once wool fibers are destroyed by chemical bases, hydrogen peroxide, $\mathrm{HCl}$, was used to quantify the percentage of wool fibers.

iv) Optical test: surface of the fibers were analyzed and compared to reference standard for identification of fiber material.

The waste fibers $(\mathrm{F})$ consisted of the following composition (Table 1):

Table 1. Waste fibers composition

\begin{tabular}{cccc}
$\begin{array}{c}\text { Cellulose, which } \\
\text { most likely is cotton }\end{array}$ & Polyester & Wool & $\begin{array}{c}\text { Polypropylene, Polyamide, } \\
\text { among others }\end{array}$ \\
\hline $85 \%$ & $10 \%$ & $2 \%$ & $3 \%$ \\
\hline
\end{tabular}

For the preparation of the mortars two different washed sands were used as aggregates - a coarser sand $0 / 4 \mathrm{~mm}(\mathrm{CS})$ and a finer sand $0 / 2 \mathrm{~mm}$ (FS), both generally used in the region for mortar preparation. Two different binders were used - a powder air-lime CL90 commercialized by Lusical (L) and a Portland cement CEM II/B-L 32,5N commercialized by Secil (C). Volumetric and mass composition of lime and cement mortars are registered in Table 2. Mortars of each binder type have been made without waste fibrous material and with the addition of waste fibers in different percentages of the binder mass $-0,125 \%, 0,25 \%$ and $0,5 \%$. With each type of binder four mortars were prepared; with air-lime, mortar L without fibers; mortar LF1 with 0,125\% of waste fibers; mortar LF2 with $0,25 \%$ of fibers and mortar LF3 with $0,5 \%$ of fibers; with cement, mortar C without fibers; mortar CF1 with 0,125\% fibers; mortar CF2 with 0,25\% fibers and mortar CF3 with $0,5 \%$ of fibers, according to Table 2. 
Table 2. Mortars composition

\begin{tabular}{|c|c|c|c|c|}
\hline Mortar ID & $\begin{array}{l}\text { Volumetric } \\
\text { composition }\end{array}$ & $\begin{array}{c}\text { Mass } \\
\text { composition }\end{array}$ & $\begin{array}{c}\text { Waste } \\
\text { fibers [\%] }\end{array}$ & Mortar Mix \\
\hline $\mathrm{C}$ & \multirow{4}{*}{$1: 6$} & \multirow{4}{*}{$\begin{array}{c}1: 7 \\
1: 3: 6(\mathrm{C}: F S: C S)\end{array}$} & 0 & Coarse sand (CS) \\
\hline CF1 & & & 0,125 & Fine sand (FS) \\
\hline $\mathrm{CF} 2$ & & & 0,25 & CEM II/B-L 32,5N \\
\hline CF3 & & & 0,5 & Water/Binder =1,4 \\
\hline $\mathrm{L}$ & \multirow{4}{*}{$1: 3$} & \multirow{4}{*}{$\begin{array}{c}1: 12 \\
1: 4: 8 \text { (L:FS:CS) }\end{array}$} & 0 & Coarse sand (CS) \\
\hline LF1 & & & 0,125 & Fine sand (FS) \\
\hline LF2 & & & 0,25 & Powder air-lime CL90 \\
\hline LF3 & & & 0,5 & Water/Binder =2,4 \\
\hline
\end{tabular}

The mixture of the mortar components was mechanical and always identical between the mortars with the same type of binder (Figure 2). For air-lime mortars the water was added in the mechanical mortar mixer tank, followed by the air-lime and the sands (previously hand homogenized). The mechanical mixer worked for 30 seconds at low speed, the material at the border and bottom of the tank was scraped and the mixer worked for another 3 minutes. The procedure was based on EN 1015-2 [6] but the period of mixture was enlarged because, in previous works [7], the one defined in the standards was considered inadequate for air-lime mortars. For cement mortars the time defined in the standards was followed. With each mortar several samples were produced. The mortar samples were mechanically compacted in two layers inside prismatic metallic moulds with $40 \times 40 \times 160 \mathrm{~mm}$. Each mortar was applied over two ceramic bricks, falling from a defined height, in order to standardize the energy of application of the mortar over the brick (Figure 2) and regularized as a render.
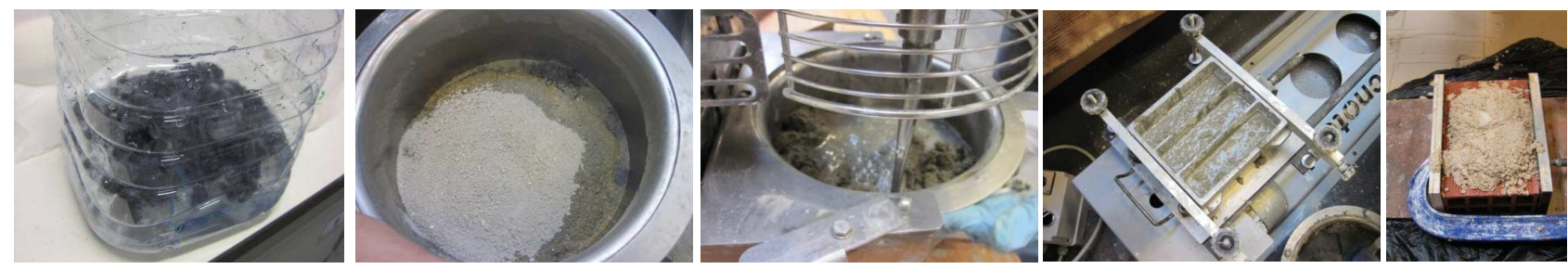

Figure 2. Mortar production

The samples of each air-lime mortar were cured until the age of test, at 28 days, inside a conditioned chamber at $20^{\circ} \mathrm{C}$ temperature and $65 \%$ relative humidity. Three days before the age of test, in order to accelerate its cure, the curing environment had an increase in carbon dioxide to $5 \%$. At the age of test, the samples were dried inside an oven at $60^{\circ} \mathrm{C}$ until constant mass - weight variation not higher than $0,1 \%$ in $24 \mathrm{~h}$ - and then tested. The samples of cement mortar were cured until the age of test, also at 28 days, at saturated environment. At the age of test, the process was identical to the air-lime mortars.

\section{Testing program and results}

The water added to each binder type mortar was always the same but different between air-lime and cement mortars. The water added intended to provide the mortars good workability for application in in situ condition. The influence of the amount of water in the fresh mortars was evaluated by the consistency flow table test [8] and the consistency by plunger penetration test [9].

At the age of test samples of each mortar were used to dynamic modulus of elasticity determination by fundamental resonance frequency [10], three points bending flexural and compressive strength determination [11]. Five squared incisions were made on each ceramic brick rendering mortar and the adhesive strength to the bricks was determined [16]. In terms of physical properties, mortar samples were used for capillary water absorption determination - capillary 
coefficient in terms of initial capillary absorption velocity and the asymptotic value in terms of total capillary absorption $[12,13]$. When completely saturated by capillary water the samples were used for the drying index determination [14, 15]. During drying, samples were kept in controlled environment.

Test results of consistency of fresh mortars and mechanical and physical characteristics of hardened mortars are presented in Table 3 and 4.

Table 3. Test results of dynamic modulus of elasticity, flexural and compressive strength, and adherence strength of mortars (StdDv - Standard Deviation).

\begin{tabular}{ccccccccc} 
& $\begin{array}{c}\mathrm{E} \\
{[\mathrm{MPa}]}\end{array}$ & StdDv & $\begin{array}{c}\mathrm{R}_{\mathrm{c}} \\
{[\mathrm{MPa}]}\end{array}$ & StdDv & $\begin{array}{c}\mathrm{R}_{\mathrm{f}} \\
{[\mathrm{MPa}]}\end{array}$ & StdDv & $\begin{array}{c}\text { Adhesive } \\
\text { strength [MPa }]\end{array}$ & StdDv \\
\cline { 2 - 9 } C & 7986 & 601 & 3,78 & 0,23 & 1,13 & 0,14 & 0,52 & 0,25 \\
\hline CF1 & 8978 & 302 & 4,14 & 0,32 & 1,29 & 0,10 & 0,45 & 0,15 \\
\hline CF2 & 7343 & 323 & 3,77 & 0,26 & 0,99 & 0,06 & 0,27 & 0,09 \\
\hline CF3 & 7750 & 76 & 3,83 & 0,11 & 1,21 & 0,06 & 0,35 & 0,06 \\
\hline L & 4938 & 117 & 1,59 & 0,21 & 0,50 & 0,14 & 0,06 & 0,03 \\
\hline LF1 & 4689 & 31 & 1,66 & 0,01 & 0,60 & 0,08 & 0,06 & 0,02 \\
\hline LF2 & 4477 & 113 & 1,67 & 0,07 & 0,52 & 0,09 & 0,04 & 0,02 \\
\hline LF3 & 4378 & 121 & 1,59 & 0,12 & 0,56 & 0,05 & 0,04 & 0,02 \\
\hline
\end{tabular}

Table 4. Test results of consistency by flow table and plunger penetration, maximum values of capillary absorption, capillary coefficient and drying index of mortars (StdDv - Standard

Deviation).

\begin{tabular}{cccccccccc} 
& $\begin{array}{c}\text { Flow } \\
{[\mathrm{mm}]}\end{array}$ & StdDv & $\begin{array}{c}\text { Plunger } \\
{[\mathrm{mm}]}\end{array}$ & StdDv & $\begin{array}{c}\text { Capillary Absorp. } \\
{\left[\mathrm{kg} / \mathrm{m}^{2}\right]}\end{array}$ & StdDv & $\begin{array}{c}\text { Capillary Coef. } \\
{\left[\mathrm{kg} / \mathrm{m}^{2} \cdot \mathrm{min}^{0,5}\right]}\end{array}$ & $\begin{array}{c}\text { Drying } \\
\text { index }\end{array}$ & StdDv \\
\cline { 2 - 11 } C & 130 & 1 & 177 & 21 & 16,60 & 1,11 & 1,39 & 0,39 & 0,13 \\
\hline CF1 & 143 & 4 & 175 & 10 & 15,72 & 0,18 & 1,11 & 0,43 & 0,02 \\
\hline CF2 & 151 & 9 & 150 & 26 & 16,40 & 0,20 & 1,41 & 0,48 & 0,02 \\
\hline CF3 & 136 & 3 & 167 & 31 & 16,91 & 0,73 & 1,26 & 0,45 & 0,04 \\
\hline L & 156 & 2 & 163 & 0 & 14,71 & 0,19 & 1,12 & 0,77 & 0,04 \\
\hline LF1 & 157 & 0 & 178 & 1 & 15,06 & 0,72 & 1,15 & 0,75 & 0,02 \\
\hline LF2 & 154 & 4 & 165 & 1 & 14,77 & 0,30 & 1,14 & 0,80 & 0,02 \\
\hline LF3 & 157 & 1 & 173 & 0 & 14,36 & 0,44 & 1,11 & 0,78 & 0,03 \\
\hline
\end{tabular}

\section{Discussion and conclusions}

Cement-based mortars present an average flow consistency of 140mm (StdDv 9,10) and average plunger penetration consistency of $167 \mathrm{~mm}$ (StdDv 2,2). Air lime-based mortars present an average flow consistency of $156 \mathrm{~mm}$ (StdDv 1,41) and plunger penetration consistency of $170 \mathrm{~mm}$ (StdDv $0,7)$. The presence of fibers increases the flow consistency of cement-based mortars while plunger penetration decreases. Lime-based mortars flow consistency seems to not be affected by the usage of waste fibers. Nevertheless the lime-based mortars plunger penetration is slightly increased due to the use of fibers.

According to Table 3 and Figure 3, it can be verified that, as expected, cement-based mortars, despite the percentage of fiber content, present higher mechanical behavior than lime-based mortars. On cement-based mortars the influence of waste fiber content on the mechanical parameters evaluated do not follow a clear trend. Except for CF2, flexural and compressive 
strengths increase with the presence of waste fibers. Cement-based mortar CF1, with $0,25 \%$ of waste fibers, presented the highest modulus of elasticity, flexural and compressive strength. It was also CF1 the mortar that exhibits the highest adhesive strength. On the other hand, CF2 present the lowest values of modulus of elasticity, flexural and compressive strength, as well as for adhesive strength. In what concerns lime-based mortars, it can be verified that flexural and compressive strengths increase with the usage of waste fibers. LF1, with $0,25 \%$ of waste fibers, presents one of the most well-adjusted mechanical behavior. For mortars produced with powder air lime, it is clear that the increase for waste fibers content decreases the mortars modulus of elasticity. The trends of flexural and compressive strength do not follow that of the elastic modulus. Nevertheless, LF3 presents the lowest modulus of elasticity, compressive strength and adhesive strength.

Regarding the physical parameters (Table 4 and Figure 3), the capillary absorption of cementbased mortars increases with the increase of fiber content while in lime-based mortars same trend cannot be identified. Cement-based mortars present an average capillary absorption of $16,41 \mathrm{~kg} / \mathrm{m}^{2}$ (StdDv 0,50) and air lime-based mortars of $14,72 \mathrm{~kg} / \mathrm{m}^{2}$ (StdDv 0,29). CF1 presents the lowest capillary coefficient and the second lowest drying index. CF2 presents the highest capillary coefficient and the highest drying index. Except of LF1, fibers increases the mortars capillary coefficient and drying index. LF3 is also the mortar with lowest capillary absorption and capillary coefficient. Among lime-based mortars, LF1 presents the lowest drying index.

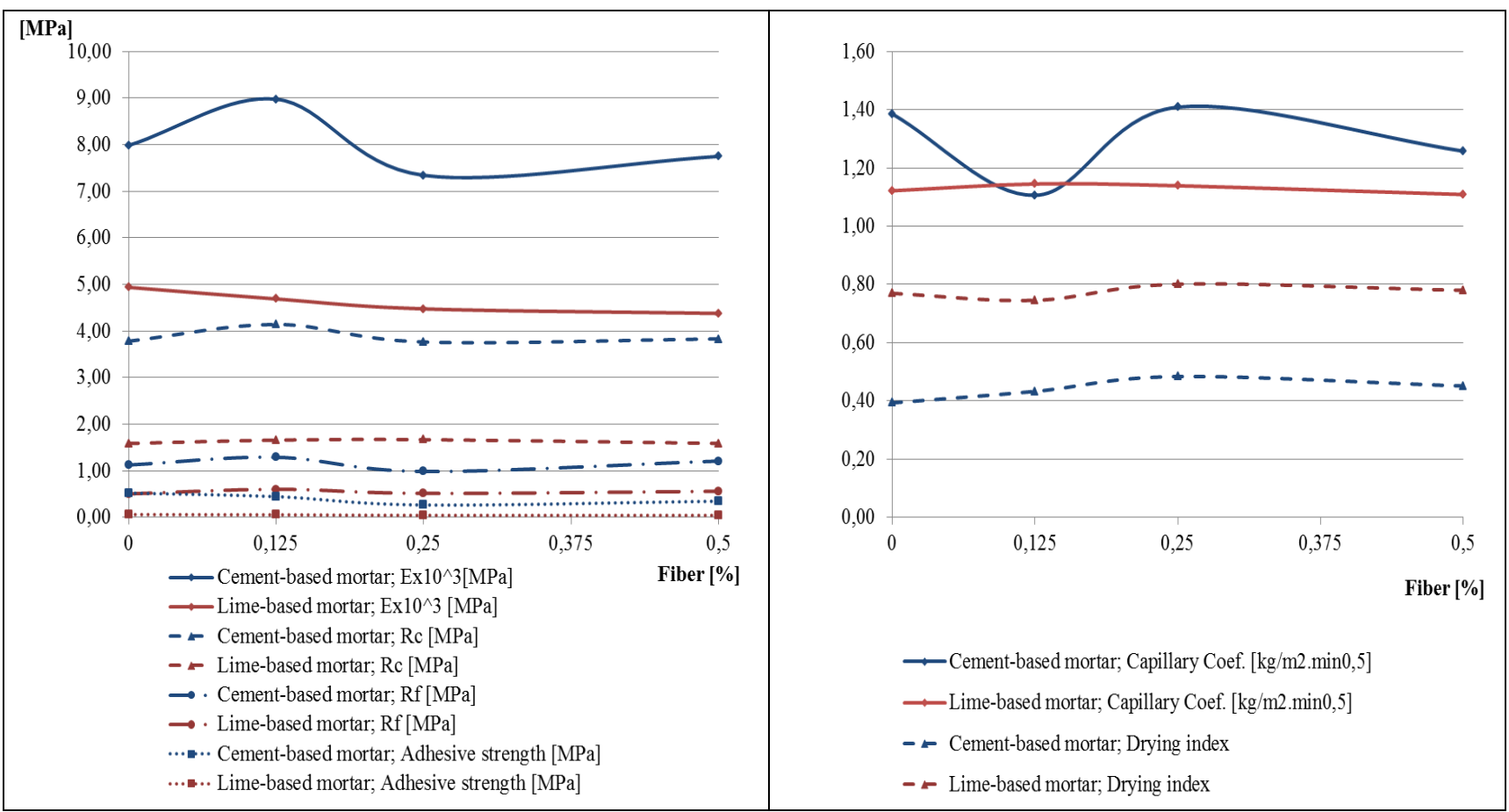

Figure 3. Test results of dynamic modulus of elasticity, flexural and compressive strength, adherence strength, capillary coefficient and drying index of mortars.

In sum, the experimental campaign put in evidence several aspects. Between the two methods used to evaluate the consistency the first seem to be more appropriate to evaluate the water influence on the mortars. The increase of fiber content decreases de dynamic modulus of elasticity; increases mortar flexural and compressive strength (except CF2); increases drying index (except LF1); decreases pull-off strength; it seems that the presence of waste fibers does not influence capillary absorption and capillary coefficient. In what concerns binder type, it can be evidenced a higher workability of air lime-based; a superior mechanical performance of cement-based mortars; improved physical performance of air lime-based mortars.

The addition of this type of fibers can optimize mortars characteristics and complementary mortars will be made with other percentages of fibers addition. Also complementary tests will be 
made in order to evaluate other physical characteristics, namely open porosity and the durability of mortars to aggressive actions like frost and salts attack.

\section{References}

[1] AABMCI, Overconsumption? Our use of the world's natural resources, Working Committee "Forum mineralische Rohstoffe" of the Austrian Association for Building Materials and Ceramic Industries, Austria (2009).

[2] Segre, N., Tonella E. , and Joekes, I. ,Evaluation of the stability of polypropylene fibers in environments aggressive to cement-based materials, Cement and Concrete Research 28 (1998), pp. 75-81.

[3] Veiga, M.R., Behavior of rendering mortars. Contribution to evaluate the cracking susceptibility (in Portuguese), $\mathrm{PhD}$ thesis, Oporto University (1997).

[4] Puertas, F., Amat, T., Fernandez-Jimenez A., and Vazquez, T., Mechanical and durable behaviour of alkaline cement mortars reinforced with polypropylene fibres, Cement and Concrete Research 33 (2003), pp. 2031-2036.

[5] Lundahl, A., Study on the waste fiber reinforced ecocomposites, MSc thesis, E-TEAM European Masters in Textile Engineering, university of Minho (2008).

[6] CEN, Methods of test for mortars for masonry. Part 2: Bulk sampling of mortars and preparation of test mortars. Brussels, EN 1015-2: 1998/A1: 2006.

[7] P. Faria, F.M. Henriques, V. Rato, Comparative evaluation of aerial lime mortars for architectural conservation, J. Cultural Heritage 9 (2008) 338-346.

[8] CEN, Methods of test for mortars for masonry. Part 3: Determination of consistency of fresh mortar (by flow table). Brussels, EN 1015-3: 1999/ A1: 2004/ A2: 2006.

[9] CEN, Methods of test for mortar for masonry. Part 4: Determination of consistence of fresh motar (by plunger penetration). EN 1015-4: 1998.

[10] CEN, Natural stone test methods. Determination of the dynamic modulus of elasticity (by measuring the fundamental resonance frequency). Brussels, EN 14146: 2004.

[11] CEN, Methods of test for mortars for masonry. Part 11: Determination of flexural and compressive strength of hardened mortar. Brussels, EN 1015-11: 1999/ A1: 2006.

[12] CEN, Methods of test for mortars for masonry. Part 18: Determination of water absorption coefficient due to cappilary action of hardened mortar. Brussels, EN 1015-18: 2002.

[13] CEN, Conservation of cultural property. Test methods. Determination of water absorption by capillary. Brussels, EN 15801: 2009.

[14] Commissione Normal, Misura dell'indice di asciugamento (drying index). Roma, CNR/ICR, Doc. $29 / 88$.

[15] V. Brito, T.D. Gonçalves, P. Faria, Coatings applied on damp substrates: performance and influence on moisture transport. J. Coating Technology and Research (2011,.doi: 10.1007/s11998-010-9319-5).

[16] CEN, Methods of test for mortar for masonry. Part 12: Determination of adhesive strength of hardened rendering and plastering mortars on substrates. EN 1015-12: 2000. 